\title{
CUTICULAR UPTAKE OF GLYPHOSATE INTO WHEAT WITH ORGANOSILICONE SURFACTANT
}

\author{
Z.Q. LIU and J.A. ZABKIEWICZ \\ Plant Protection Chemistry, NZ Forest Research Institute, Rotorua
}

\begin{abstract}
Droplet spread areas on wheat leaves were determined for a range of solutions containing Silwet L-77 surfactant. In combination with added glyphosate at different concentrations, this provided a range of dosages of glyphosate per unit leaf area. Uptake varied with both surfactant and glyphosate concentrations but the controlling factor was the mass of glyphosate per area, as the uptake was identical for equivalent dosages applied. Uptake peaked at approximately $90 \%$ within $4 \mathrm{~h}$ when dosages equalled or exceeded $2 \mu \mathrm{g} / \mathrm{mm}^{2}$.
\end{abstract}

Keywords: glyphosate, cuticular uptake, wheat, organosilicone surfactant.

\section{INTRODUCTION}

The enhanced uptake of glyphosate with organosilicone surfactants into plants is well documented. This is primarily by infiltration of stomata. However, there are apparent exceptions with several grass species (Field et al. 1992; Gaskin and Stevens 1992) where no such obvious enhancement can be demonstrated. It has also been well established with various plant species that glyphosate uptake generally increases with increasing concentration of the herbicide (Townson and Butler 1990) or decreased carrier volumes (Knoche 1994). These effects were observed with glyphosate formulations without added organosilicones. Any information on the influence of organosilicones on the cuticular uptake enhancement of glyphosate has been indirect and varied with organosilicone surfactant (Gaskin and Zabkiewicz 1989; Stevenset al.1992). However, it has been shown recently that organosilicone surfactants can penetrate rapidly into leaves (Zabkiewicz et al. 1995), by a presumed cuticular diffusion mechanism. The present study examines the influence of an organosilicone surfactant, Silwet L-77, on glyphosate uptake into the foliage of a model grass species, wheat, when used at concentrations that do not facilitate stomatal infiltration, and at varying ratios of glyphosate: surfactant.

\section{Wheat plants}

\section{METHODS AND MATERIALS}

Wheat plants (Triticum aestivum L, cv Advantage) were raised from seed in a controlled environment as reported previously (Zabkiewiczet al. 1995) for 4 weeks until they reached the 4-5 leaf growth stage.

\section{Spread areas}

Droplets of Silwet L-77 solution $(0.24 \mu \mathrm{l})$ containing $0.5 \%$ fluorescent dye (Blankophor, Bayer) were applied to the adaxial surfaces of wheat leaves with a microsyringe at concentrations of $0.01 \%$ to $0.2 \%$ surfactant. The spread area of droplets on the leaf surface was measured using $\mathrm{V}$ for Windows image analysis system. A minimum of 12 replicates was used for each set of determinations.

\section{Glyphosate uptake}

$\left[{ }^{14} \mathrm{C}\right]$ Glyphosate (Amersham, specific activity $1.9 \mathrm{GBq} / \mathrm{mmol}$ ) was added to unlabelled glyphosate IPA at less than $0.2 \%$ of total glyphosate concentration. An appropriate amount of the mixture was used to make up solutions of known glyphosate concentration. Silwet L-77 (silicone polyalkyleneoxide copolymer, OSi Specialties) in water was added to glyphosate treatment solutions immediately prior to use in appropriate amounts, to provide the desired concentrations and ratios. 


\section{Treatments}

Twelve droplets $\mathrm{x} 0.24 \mu \mathrm{l}$ were applied by microsyringe to the adaxial surface of fully expanded (youngest) wheat leaves (five replicates of individual plants). Glyphosate, dissolved in 1:1 water:acetone to assist droplet retention, was also applied to the leaves for comparison. Uptake was determined by washing residual glyphosate from the leaf surfaces after specific intervals and calculating the amount absorbed as described previously (Gaskin 1995). All uptake data were subjected to analysis of variance and LSD determinations for comparisons between different treatments.

\section{RESULTS}

The application of treatments to wheat leaves showed that spread area increased with increasing surfactant concentration (Table 1).

TABLE 1: Spread areas, and uptake of glyphosate (as \% of applied) from solutions with Silwet L-77, into wheat leaves after $24 \mathrm{~h}$.

\begin{tabular}{cccccc}
\hline & Spread & \multicolumn{5}{c}{ Glyphosate concentrations (\% w/v) } \\
Silwet L-77 & $\begin{array}{c}\text { areas } \\
(\%)\end{array}$ & 0.5 & 1.25 & 2.5 & 5.0 \\
\hline $\left.\mathrm{mm}^{2}\right)$ & 0.9 & 44 & 61 & 54 & 29 \\
0.00 & 1.3 & 79 & 92 & 94 & 97 \\
0.01 & 2.5 & 67 & 85 & 92 & 93 \\
0.02 & 5.8 & 32 & 61 & 79 & 87 \\
0.05 & 10.8 & 23 & 46 & 60 & 75 \\
0.10 & 22.9 & 17 & 25 & 39 & 67 \\
0.20 & & & & & \\
\hline
\end{tabular}

$\mathrm{LSD}=10.2(\mathrm{P}=0.05)$ for the glyphosate uptake results.

Glyphosate uptake results at $24 \mathrm{~h}$ after application are also presented in Table 1 . With the exception of the nil-surfactant treatments, the uptake increased as the concentration of Silwet L-77 decreased, within any one glyphosate concentration series.

The calculated dosages of glyphosate, applied at differing concentrations of active and surfactant, are presented for each formulation combination in Table 2. It can be observed that these form an overlapping sequence with increasing glyphosate dosages within each series.

TABLE 2: Calculated dosages of glyphosate $\left(\mu \mathrm{g} / \mathrm{mm}^{2}\right)$ for each combination of glyphosate and Silwet L-77 on wheat leaves.

\begin{tabular}{ccccc}
\hline & \multicolumn{4}{c}{ Glyphosate concentrations $(\% \mathrm{w} / \mathrm{v})$} \\
Silwet L-77 $(\%)$ & 0.5 & 1.25 & 2.5 & 5.0 \\
\hline 0.00 & 1.32 & 3.30 & 6.59 & 13.18 \\
0.01 & 0.95 & 2.38 & 4.76 & 9.52 \\
0.02 & 0.49 & 1.22 & 2.45 & 4.90 \\
0.05 & 0.21 & 0.52 & 1.03 & 2.06 \\
0.10 & 0.11 & 0.28 & 0.56 & 1.11 \\
0.20 & 0.05 & 0.13 & 0.26 & 0.53 \\
\hline
\end{tabular}

It can be seen that in Table 2 there is a close correspondence of applied dosages, represented diagonally (top left to bottom right) across the glyphosate/surfactant treatments (except for the nil-surfactant solutions), for the various combinations.

Again, except for the nil-surfactant solutions, the uptake of glyphosate, into wheat leaves after $24 \mathrm{~h}$, can be related to the applied dosage. There is a very rapid increase in uptake as the dosage rises from less than $0.5 \mu \mathrm{g} / \mathrm{mm}^{2}$, to approximately $2 \mu \mathrm{g} / \mathrm{mm}^{2}$ (Fig. 1). After that point, where there is approximately $90 \%$ uptake, further increases due to 
higher dosages of glyphosate are minimal. A regression analysis of the data gave $\mathrm{R}^{2}=$ 0.92 .

An equivalent uptake series is also evident, with close correspondence of uptake at equivalent applied dosages e.g. all formulations at approximately $0.5 \mu \mathrm{g} / \mathrm{mm}^{2}$ show an uptake of around $60 \%$ (Tables 1 and 2).

The rate of uptake of glyphosate from selected formulations is shown in Fig. 2. The nil-surfactant solution of $1 \%$ glyphosate in water:acetone shows the typical rate of uptake previously determined. The rates of uptake of glyphosate at $1 \%$ and $2 \%$, plus equivalent surfactant concentrations respectively, i.e. at equivalent applied dosages per unit leaf

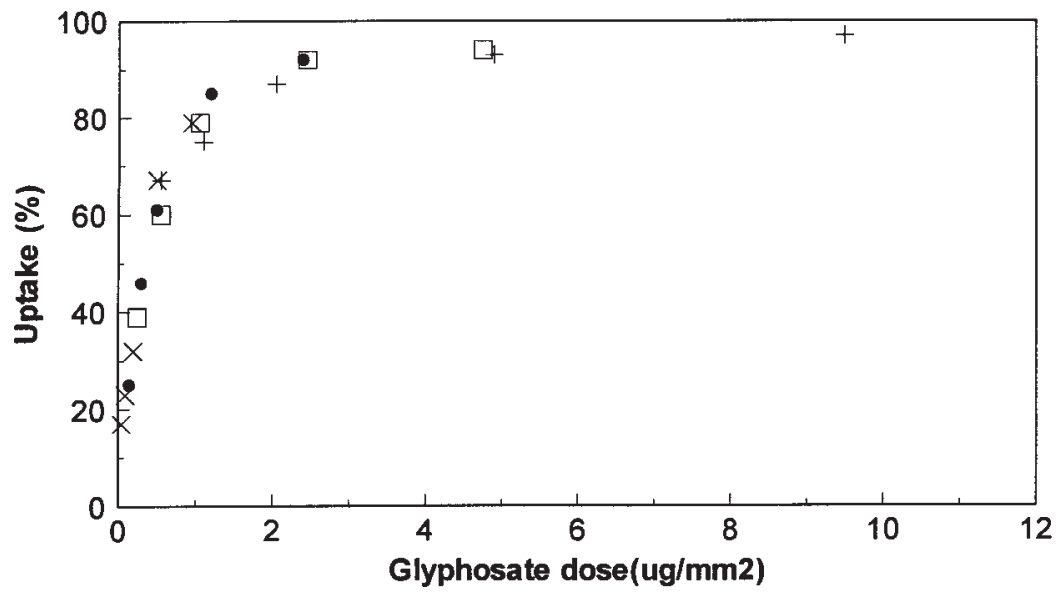

FIGURE 1: Uptake of glyphosate after $24 \mathrm{~h}$ into wheat: $0.5 \%$ glyphosate series (5); $1.25 \%$ glyphosate series (I); $2.5 \%$ glyphosate series (0); $5 \%$ glyphosate series (+).

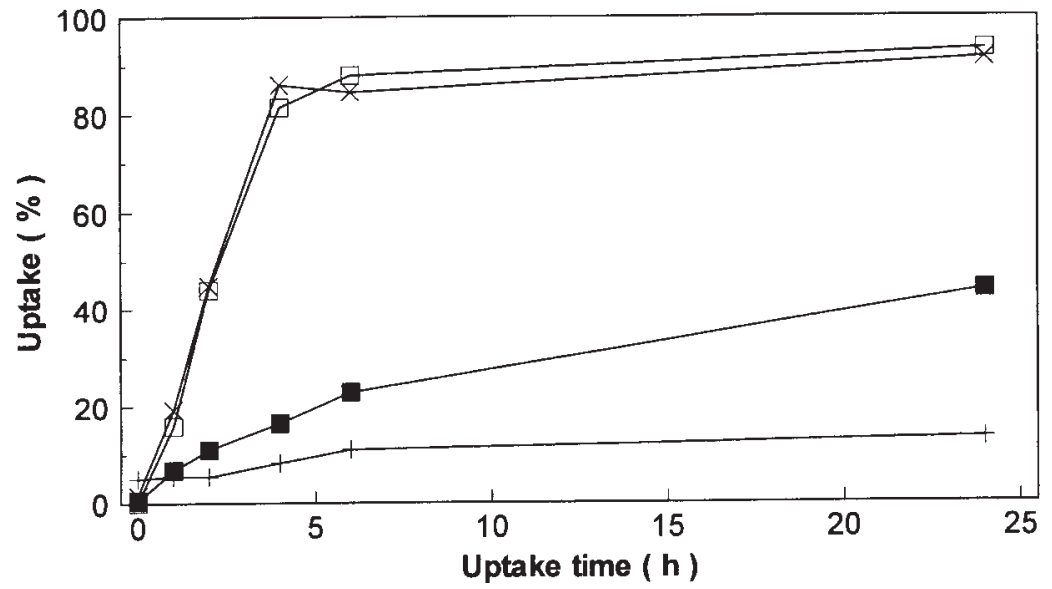

FIGURE 2: Uptake of selected glyphosate formulations after 24h into wheat: $1 \%$ glyphosate $+0.01 \%$ surfactant $(5) ; 2 \%$ glyphosate $+0.02 \%$ surfactant (o); $1 \%$ glyphosate in water:acetone $(n) ; 1 \%$ glyphosate $+\mathbf{0 . 2 \%}$ surfactant $(+)$. 
area, show much faster uptake, with approximately $90 \%$ uptake after $4 \mathrm{~h}$. This is in contrast to approximately only $10 \%$ uptake of $1 \%$ glyphosate from the formulation with $0.2 \%$ added Silwet L-77, similar to that observed in earlier studies (Gaskin and Stevens 1992).

\section{DISCUSSION}

The low concentrations of Silwet L-77 used in the present formulations are insufficient to provide rapid stomatal infiltration, so any enhancement of uptake should be by a cuticular diffusion mechanism. Direct evidence of a lack of stomatal infiltration of these solutions has recently been provided through the use of confocal microscopy to observe the behaviour of such solutions on leaf surfaces (Gaskin et al. 1997).

The concentration of Silwet L-77 surfactant determines the extent of droplet spreading, from minimal to quite extensive (Table 1), a property not available with conventional organic surfactants due to their higher solution surface tension. Accordingly, the mass of glyphosate per unit area of leaf surface (expressed in $\mu \mathrm{g} / \mathrm{mm}^{2}$ ) can be manipulated (Table 2), and the uptake from each formulation determined (Table 1). Previous studies could only alter the glyphosate concentration (Townson and Butler 1990), or manipulate droplet size (Knoche 1994; Liu et al. 1996), and thus demonstrate that increased glyphosate concentration or decreased droplet size enhanced uptake of glyphosate into plants. In practice, higher application rates mean higher costs and smaller droplets have a higher risk of spray drift, so neither is an ideal practical option. The ability to increase uptake, while keeping glyphosate concentrations constant, as well as reduce the amount of expensive organosilicone surfactant, is a more attractive operational proposition.

In this study, as the concentration of surfactant increases, the dose of glyphosate per unit leaf surface decreases and it is clearly seen that uptake also decreases (Fig. 1). It is also clearly evident from the data (Fig. 2, Table 1) that equivalent dosages of glyphosate, even though the solutions may have different absolute concentrations of each substance, provide equal uptake. In particular, as the dosage rises to a concentration at or above 2 $\mu \mathrm{g} / \mathrm{mm}^{2}$, so uptake also increases to around $90 \%$. Any further possible increase is obviously small and there is no benefit from increasing the glyphosate dose above that level. A comparison of the rates of uptake of glyphosate from specific formulations, over a $24 \mathrm{~h}$ period, is provided in Fig. 2. As previously determined (Field et al. 1992), uptake into grasses with $0.2 \%$ Silwet L-77 can be low and the result with wheat confirms this finding. This uptake is even lower than glyphosate without added surfactant and confirms the effect of a dose dependent cuticular diffusion mechanism. In this instance, the spread area of droplets with $0.2 \%$ Silwet L- 77 is very large, and the dose per leaf area covered is very low; in addition, the concentration is not sufficiently high to permit significant stomatal infiltration. In contrast, the two formulations of glyphosate which provide a dosage in excess of $2 \mu \mathrm{g} / \mathrm{mm}^{2}$ show not only the final $90 \%$ plus uptake, but a remarkably fast uptake to that level over a period of only four hours. This is much greater and faster than the glyphosate in water:acetone solution (with a dosage of approximately $2.6 \mu \mathrm{g} / \mathrm{mm}^{2}$ ) showing that even such a low level of organosilicone surfactant is capable of inducing substantial cuticular absorption, of glyphosate and presumably surfactant with it.

\section{CONCLUSION}

It has been demonstrated that cuticular uptake enhancement of glyphosate, in the presence of much lower concentrations of organosilicone surfactant than is used typically, is substantial, provided the applied dosage per unit leaf area reaches $2 \mu \mathrm{g} / \mathrm{mm}^{2}$ or more. Glyphosate uptake is very dose dependent and adjusting the amount of added surfactant to control droplet spread, and hence applied dosage to the leaf, is a simple and cost effective option for enhancing uptake into a grass species. Near maximum uptake can be accomplished in around four hours under optimised conditions. It is however not yet established whether this principle applies to all grasses or only those with specific cuticular or stomatal characteristics.

\section{REFERENCES}


Field, R.J., Dobson, N.N. and Tisdall, L.J., 1992. Species specific sensitivity to organosilicone surfactant-enhancement of glyphosate uptake. Pp 423-431. In : Adjuvants for Agrochemicals, C.L. Foy, (Ed), CRC Press, Boca Raton.

Gaskin, R.E., 1995. Effect of organosilicone surfactants on the foliar uptake of herbicides: stomatal infiltration vs cuticular penetration. Pp 243-248.In: Fourth Int. Symp. on Adjuvants for Agrochemicals, R.E. Gaskin, (Ed), Melbourne, NZ FRI Bulletin No. 193.

Gaskin, R.E. and Stevens, P.J.G., 1992. Antagonism of the foliar uptake of glyphosate into grasses by organosilicone surfactants. Pestic. Sci.38: 185-192.

Gaskin, R.E. and Zabkiewicz, J.A., 1989. The effect of surfactants on the uptake and translocation of glyphosate in Yorkshire fog. Proc. 42nd N.Z. Plant Prot. Soc. Conf: : 128-131.

Gaskin, R.E., Murray, R., Forster, W.A. and Zabkiewicz, J.A., 1997. Visualisation of stomatal infiltration by surfactant sprays on foliage using confocal laser scanning microscopy. Proc. 50th N.Z. Plant Prot. Soc. Conf.: (this volume).

Knoche, M., 1994. Effect of droplet size and carier volume on performance of foliageapplied herbicides. Crop Prot. 13: 163-178.

Liu, S.H., Campbell, R.A., Studens, J.A. and Wagner, R.G., 1996. Absorption and translocation of glyphosate in aspen as influenced by droplet size, droplet number and herbicide concentration. Weed Sci. 44: 482-488.

Stevens, P.J.G., Gaskin, R.E., Hong, S.O. and Zabkiewicz, J.A., 1992. Pathways and mechanisms of foliar uptake as influenced by surfactants. Pp 385-398.In: Adjuvants for Agrochemicals, C.L. Foy, (Ed), CRC Press, Boca Raton.

Townson, J.K. and Butler, R., 1990. Uptake, translocation and phytotoxicity of imazapyr and glyphosate inImperata cylindrica: effect of herbicide concentration, position of deposit and two methods of direct contact application. Weed Res. 30: 235-243.

Zabkiewicz, J.A., Forster, W.A., Steele, K.D. and Liu, Z.Q., 1995. Comparison of uptake into field bean and wheat of organosilicone and non-organosilicone surfactants. $\mathrm{Pp}$ 219-224.In: Fourth Int. Symp. on Adjuvants for Agrochemicals, R.EGaskin, (Ed), Melbourne, NZ FRI Bulletin No. 193. 